\title{
Analysis of Riverbank Stability Due to Bamboo Vegetation in Walanae River, South Sulawesi, Indonesia
}

\author{
Nurlita Pertiwi ${ }^{1 *}$, Bakhrani Abdul Rauf', Mithen Lullulangi ${ }^{1}$ \\ Civil Engineering Education Faculty of Engineering, Universitas Negeri Makassar, Makassar, Indonesia \\ * Corresponding author's e-mail: nurlita.pertiwi@unm.ac.id
}

\begin{abstract}
Bamboo vegetation is an endemic plant in Indonesia that grows on riverbanks. These plants have the potential to increase shear resistance due to the bond between the roots to the soil. However, an increase in plant weight due to its growth causes additional loads of soil. The condition triggers the release of soil on the slopes and causes riverbank sliding. Therefore, in developing the riparian ecological function, it is necessary to maintain the plants without neglecting the risk of physical damage to the river. This study aimed to estimate the risk of riverbank sliding due to the presence of bamboo plants by utilizing the bamboo vegetation conditions on the Walanae River. It was carried out on the $42.4 \mathrm{~km}$ riverbank in the middle area of Walanae watershed. The researchers selected 46 clumps of parring bamboo (Gigantochloa atter) as an endemic bamboo in this area and growing in the riverbank. The diameter of the bamboo trunk is the basis for an estimate of the weight of the bamboo clump. Furthermore, a numerical analysis was carried out by taking into account the load and shear resistance on the slope, including the weight of the plant. The research results indicated that bamboo is feasible to be applied for riverbank protection using the soil bioengineering method. The bamboo weight, which is indicated by the number of poles and diameter, significantly affects the stability of the slope. Therefore, the prevention of rising weight by harvesting method is critical to consider in riverbank protection.
\end{abstract}

Keywords: slope, diameter, weight of bamboo, Walanae River.

\section{INTRODUCTION}

As an ecological sub-system, riverbanks are very vulnerable to degradation due to their internal characteristics combination and flow dynamics [McMahon et al., 2020]. Environmental restoration of the river system is one of the ecological protection options by combining the flow and soil characteristics [Rey et al., 2019]. Moreover, the high sedimentation and slides are evidence of the decreasing of the riverbank quality. Internally, it is characterized by soil, vegetation, and aquatic conditions of the river.

In contrast, the river flow dynamics are caused by high rainfall, floods, and sediment transport leads to erosion and riverbank collapse [Recking et al., 2019]. Meanwhile, the function of the riverbank as a regulator of river flow depends on its maintenance [Lu et al., 2018]. Ecologically, the river bank also acts as a riparian and is a transition zone in the aquatic zone, always wet with a terrestrial area that sometimes experiences wet or dry conditions [Schmitt et al., 2018].

The existence of vegetation on the banks of the river dramatically affects the physical processes of natural channels. The growth of plants contributes to riverbank stabilization [Bischetti et al., 2014]. However, the process of protecting slopes and their stability and their relationship to plants has not been a serious concern. The presence of large trees increases the potential for slope movement. Moreover, the dynamics of plant growth are very influential on the success of cliff protection [Cislaghi et al., 2018]. Therefore, temporal plant growth should be an essential consideration in soil bioengineering. The dynamics of root reinforcement are exciting studies in applying environmentally friendly cliff protection [Bischetti et al., 2021]. 
The plant system that includes root, stem, and leaf has a contribution to the bank stability. This contribution can change in line with the characteristics of the stand and the nature of groundwater retention. The stem and leaf system can minimize splash erosion and reduce the risk of scouring the soil. Furthermore, the root system with its growth dynamics has raised many questions about the potential of roots towards soil stability. Root growth contributes to soil shear resistance [Cislaghi et al., 2017].

The ability of plants to maintain streambank conditions depends on the depth of their roots. The natural mechanism that occurs in vegetation can technically be related to the theory of channel hydraulics. The streambank resistance or cliff reinforcement is better with the presence of plant root networks. Plant roots that coincide with the soil shear plane cause a good interaction with soil reinforcement. On the other hand, channel roughness increases along with plant roots. This condition causes a loss of energy in the flow and reduces the flow velocity. With these two mechanisms, plants strengthen riverbanks internally and externally. Plant roots also reduce external stresses due to river flow [Gasser et al., 2019].

The riverbank root systems also improve stability and maintain geometric bank conditions [Abernethy et al., 2000]. The strengthening mechanism of the cliffs with the presence of plant roots is their ability to act as anchors on the ground. Therefore, they are able to support the riverbank soil mass; moreover, and the vegetation roots produce a more robust soil matrix and increase its stability against the risk of collapse $[\mathrm{Wu}$ et al., 1998]. Although the hydrodynamic model of river flow is influenced by riverbank vegetation, this plant spreads the flow pattern in order to reduce speed. As a result, there is a kinetic energy decrease in soil mass, which reduces the risk of its release on riverbanks [Pollen et al., 2005].

The contradictory opinions about the role of plant roots on soil stability describe that: the dynamics of plants and their growth cause an increase in the risk of cliff slides [Cislaghi et al., 2018]. The increase in lateral strength due to root growth is also an interesting consideration in the study of soil bioengineering [Dietrich et al., 2007]. Another study, also described the potential for decreasing soil stability due to riparian plant root systems [Zhang et al., 2020]. The intrinsic properties of the soil or its properties affect the erosion potential of the soil. However, the growth of the root system and the accumulation of litter can change the nature and structure of the soil, which can increase the potential for cliff erosion.

Plant growth is also considered a problem at the risk of rock slides. The interaction between water flow and vegetation on the riverbank was also analyzed with a mechanical approach. The increasing shear forces due to plant growth lead to a rise in the safety factor value at a certain slope. Furthermore, plant growth, which includes roots, twigs, and leaves, practically increases soil mass. Therefore, vegetation growth increases the risk of landslides [Mao et al., 2012] and [Bordoloi et al., 2020]. Moreover, the depth of roots can affect the critical shear stress or facilitate slope failure on the riverbank [Gasser et al., 2020].

This study focused on the risk of cliff collapse due to the growth of bamboo plants along the river. The bamboo grows with various species and develops rapidly due to the dependence of the rhizome root system. Meanwhile, when not controlled, the widespread distribution of underground roots causes sprouts to grow in unwanted places. Its sustainability is due to poor maintenance or improper destruction. Bamboo is an essential part of various community activities such as building houses, traditional marriage ceremonies, and death. Furthermore, its shoots are used as local food ingredients.

The decrease in cliff stabilization on the riverbank was caused by the weight of bamboo plants (W1) and soil mass (W2). The combination of plant and soil mass is described in Figure 1. On the basis of this combination, this research was divided into two objectives. The first objective was to find the weight of bamboo estimated by the diameter of poles. The secondary aim of the study is the risk of collapse. In the slope stabilization study, the mass failure was assessed based on the value of safety factors, which indicates cliff collapse when greater than 1.25 [WSDOT, 2005].

\section{METHODS}

\section{Study area}

The location of this study was the Walanae watershed which intersects the administrative area of Soppeng Regency. The Walanae River, as the focus of this study, has a watershed area of 740 $\mathrm{km}^{2}$ and a length of $250 \mathrm{~km}$, which flows from south to north towards the Lake Tempe alluvial. 


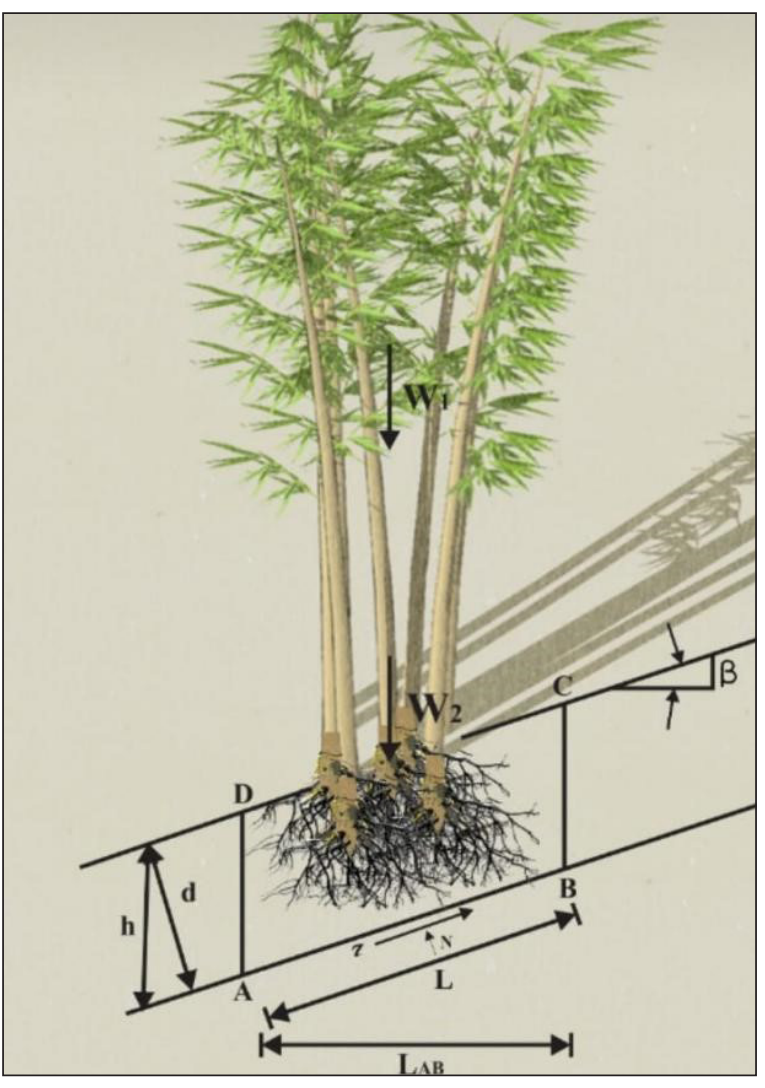

Figure 1. Description of plant weight on cliff stability

\section{Sampling procedure}

The measurement of bamboo characteristics was carried out in January 2020 - March 2020. The middle area of the Walanae River was chosen as the sampling location with a river length of $42.4 \mathrm{~km}$. There were 46 clumps of parring bamboo (Gigantochloa atter) that became the research sample. As one of the endemic species in Indonesia, bamboo grows in the riverbank of the Walanae River. Figure 3 describes the measurement of pole diameter. It started with the determination of observation points (Fig. 3a). Furthermore, Figure $3 \mathrm{~b}$ shows the point in the stem height of $150 \pm 5 \mathrm{~cm}$ [Yuen et al., T. 2017]. Figure $3 \mathrm{c}$ shows the measurement of pole diameter using a caliper.

The average value of bamboo diameter forms the basis for calculating the total plant weight using the above-ground biomass equation. Furthermore, the calculation of the importance of bamboo-based on the pole diameter using the AGB (Above Ground Biomass) equation (Eq. 1) [Yuen et al., 2017].

$$
\mathrm{AGB}=0.269 \times \mathrm{D}^{2.017}
$$

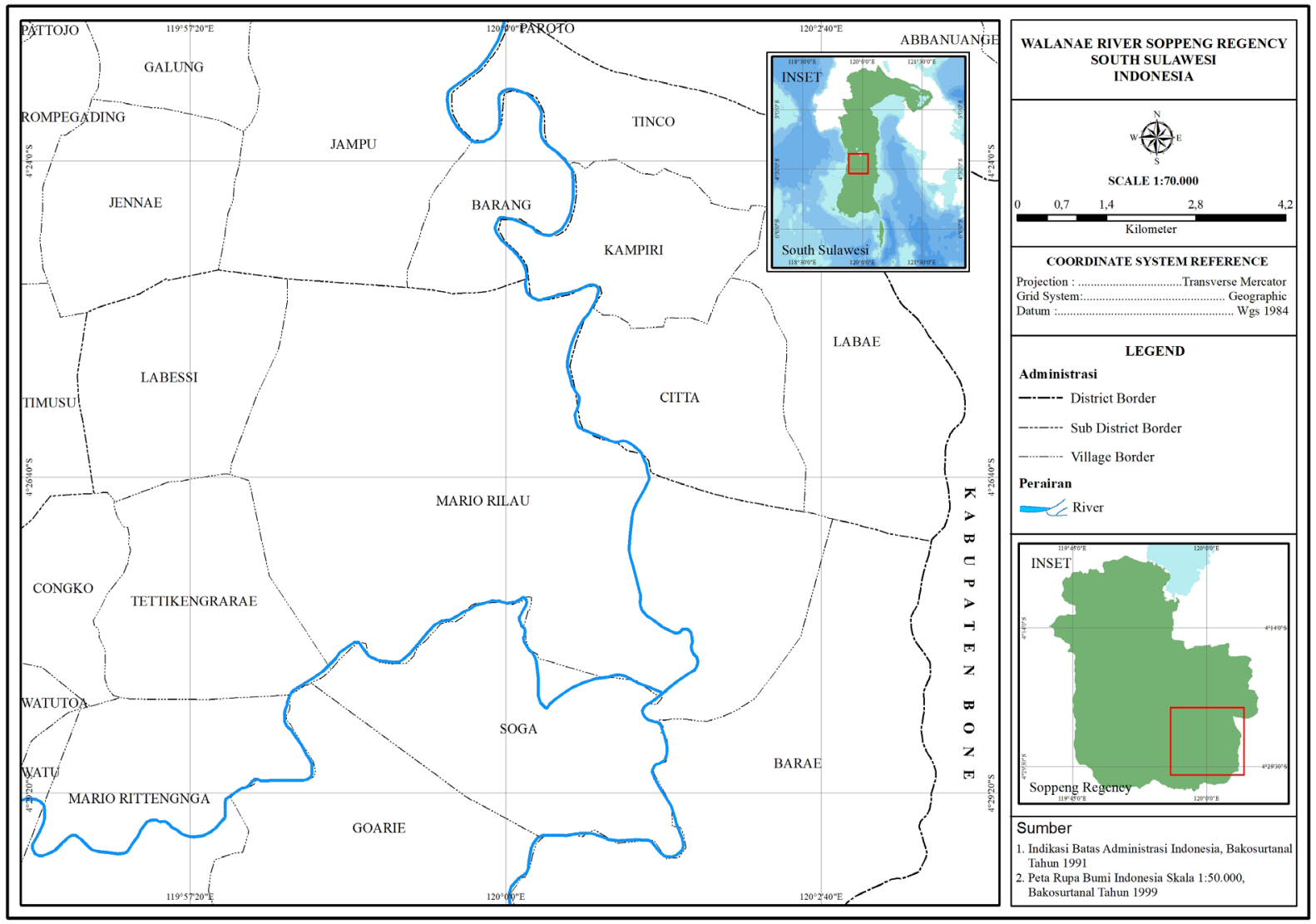

Figure 2. Field site of Walanae River 


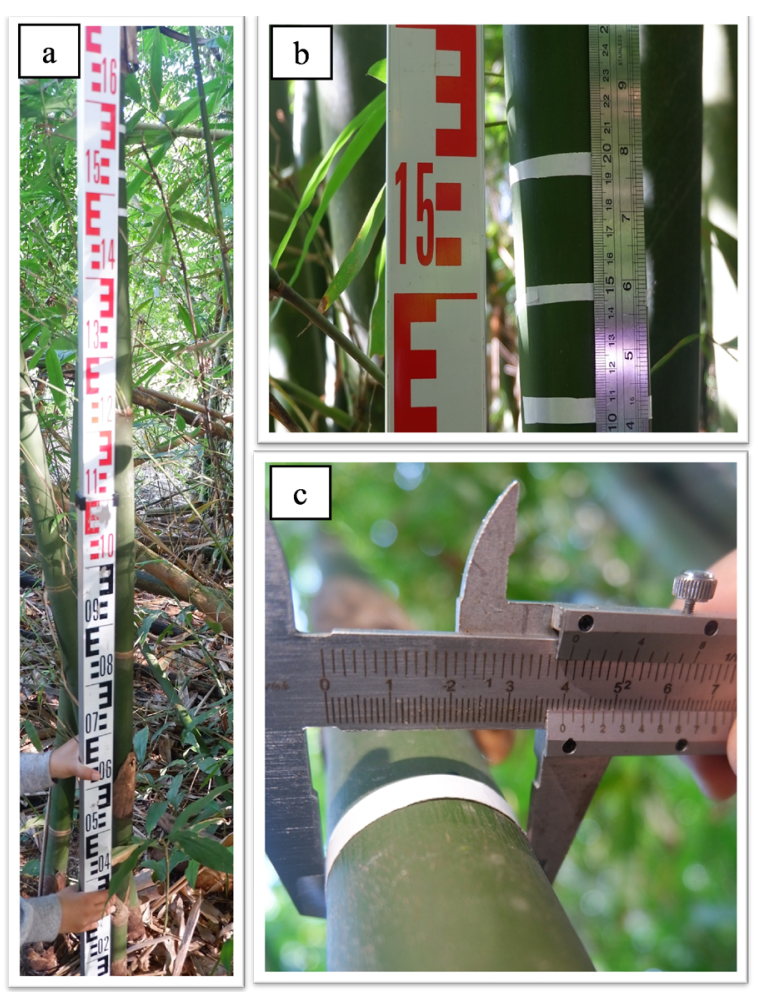

Figure 3. The Measurement of pole diameter

The weight of the bamboo clump is calculated by the sum of all pole weights in one cluster. Next, the researchers grouped bamboo into three groups, namely Psmall, Pmed, and Plarge. The bamboo weight dataset is arranged from the smallest value to the most significant value. The data structure is divided into three categories. From the results, three types of bamboo were obtained, namely small, medium and large bamboo, based on their weight category.

The target of the research was to describe the incidence of slope landslides by the additional load due to the weight of the bamboo plant. The safety factor (Fs) becomes a marker of the incident. Slope stability analysis used the ratio of shearing resistance to force [Mao et al., 2012] and [Bordoloi et al., 2020]. The numerical test of slope stability using secondary data on soil properties in Soppeng Regency is shown in Table 1. The simulation of the safety factor calculation based on the angle of the slope and size of the bamboo led to the risk of riverbank sliding, and a value greater than 1.25 indicates cliff collapse [19].

$$
F s=\frac{S}{\tau}=\frac{\left(C^{\prime}+C s\right) L+\left(W_{S}^{\prime}+W t\right) \cos \beta \tan \theta^{\prime}}{(W s+W c) \sin \beta}
$$

The determination of the input values is presented in the Table 1.

\section{RESULTS}

\section{Characteristics of bamboo vegetation in Riparian}

Bamboo plants were discovered along the Walanae River. The results of this study showed that most of the bamboo plants were the result of 3-5 years. Due to its very intensive use, bamboo is a commodity with a high selling value. The bamboo is used as building materials for traditional houses for community, local formal events, or other purposes. People tend to choose riverbanks for planting bamboo, because their crops are easily transported to different locations via rivers. In addition, this plant has resistance to standing water due to flooding. Therefore, it is considered suitable for planting in riparian areas. The calculation of pole diameter, number of poles in each clump and plant weight, and the group are presented in Table 2.

Table 2 shows that the maximum number of stems in one clump varies from 16 to 24 poles.

Table 1. Source of secondary data

\begin{tabular}{|c|c|c|c|}
\hline Variables & Unit & Value & Source \\
\hline$c^{\prime}$ (cohesion soil effective) & $\mathrm{kPa}$ & 14.7 & $\begin{array}{c}\text { Soil testing data in Walanae River (2018 } \\
\text { using ASTM D3080 }\end{array}$ \\
\hline cs (apparent cohesion due to root) & $\mathrm{kPa}$ & 7.2 & Well-developed grass cover condition $[21,22]$ \\
\hline L (bamboo root depth) & $\mathrm{m}$ & 0.3 & \\
\hline $\begin{array}{l}\text { W's (unit weight of soil minus } \\
\text { buoyancy) }\end{array}$ & $\mathrm{kN} / \mathrm{m}^{2}$ & $\begin{array}{c}\text { Equation } \\
(\partial \mathrm{s}-\partial \mathrm{w}) h \\
\partial \mathrm{s}=13.83 \mathrm{kN} / \mathrm{m} 3 \\
\partial \mathrm{w}=9.8 \mathrm{kN} / \mathrm{m} 3\end{array}$ & \multirow[t]{3}{*}{$\begin{array}{l}\partial s \text { from soil testing data in Walanae River } \\
\text { (2018) using ASTM D854 - } 14\end{array}$} \\
\hline W's (unit weight of soil) & $\mathrm{kN} / \mathrm{m}^{2}$ & Equation $(\partial \mathrm{s}) h$ & \\
\hline B (slope) & 0 & simulation & \\
\hline$\varnothing^{\prime}$ (friction angle) & $\mathrm{o}$ & 34.83 & $\begin{array}{c}\text { Soil testing data in Walanae River (2018) } \\
\text { using ASTM D3080 }\end{array}$ \\
\hline
\end{tabular}


Table 2. Characteristic of bamboo

\begin{tabular}{|l|l|l|l|}
\hline Characteristic & Maximum & Minimum \\
\hline Number of poles in one culm & 16 & 27 \\
\hline \multicolumn{2}{|l|}{ Diameter pole $(\mathrm{cm})$} & 0.4 & 6.3 \\
\hline \multicolumn{2}{|l|}{ Weight of bamboo $(\mathrm{kg})$} & 35.514 & 98.946 \\
\hline \multirow{3}{*}{$\begin{array}{l}\text { The weight of bamboo } \\
(\mathrm{kg})\end{array}$} & Psmall & 35.514 & 55.393 \\
\cline { 2 - 4 } & Pmed & 57.468 & 74.805 \\
\cline { 2 - 4 } & Plarge & 79.210 & 98.946 \\
\hline
\end{tabular}

The largest diameter is $6.3 \mathrm{~cm}$, and the smallest is $0.4 \mathrm{~mm}$, then the weight of bamboo in one clump is between $35.514 \mathrm{~kg}$ and $98.946 \mathrm{~kg}$. Three groups categorize bamboo, namely Psmall, Pmed, and Plarge. The weight of bamboo in the small category is between $35.514 \mathrm{~kg}$ and $55.393 \mathrm{~kg}$. Moreover, the weight of medium bamboo (Pmed) is between $57.468 \mathrm{~kg}$ and $74.805 \mathrm{~kg}$. Plarge bamboo weights between $79.210 \mathrm{~kg}$ and $98.946 \mathrm{~kg}$.

Table 3 show the number of poles (NP), weight, the largest pole diameter (DPmax), and the minor pole diameter (DPmin).

The number of bamboo samples in the Psmall group was 19 clumps with an average weight of $46.538 \mathrm{~kg}$. In turn, Pmed showed an average weight of $63.271 \mathrm{~kg}$ from 20 poles, there were only seven clumps in the Plarge group with an average weight of $88.689 \mathrm{~kg}$.

\section{Slope stability analysis}

Slope stability is an essential factor in riverbank protection. Meanwhile, vegetation existence on riverbanks is also one of the factors that reduce slope stability. Therefore, the greater the soil mass, the higher the potential of increasing the risk of landslides. This was exacerbated by the addition of vegetation mass which increases along with growth. Furthermore, the estimated weight, which refers to the diameter of the constituent rods, was proven to affect the risk of landslides. Therefore, the value of the safety factor is an indicator of the level of slope stability.

The results of the safety factor analysis on three bamboo groups with various slopes are presented in Figure 4.

Figure 4 shows the decrease of the safety factor value due to an increase in the slope angle. It proves that the larger the slope angle caused, the more extensive the risk of collapse. Psmall gives the most significant Fs value or indicates a small landslide risk in the bamboo with an average weight of $46.538 \mathrm{~kg}$. If the growth of bamboo
Table 3. The weight and diameter of bamboo

\begin{tabular}{|c|c|c|c|c|}
\hline \multicolumn{6}{|c|}{ The weight and diameter of small bamboo } \\
\hline No & NP & $\begin{array}{c}\text { Weight } \\
(\mathrm{kg})\end{array}$ & $\begin{array}{c}\text { DPmin } \\
(\mathrm{cm})\end{array}$ & $\begin{array}{c}\text { DPmax } \\
(\mathrm{cm})\end{array}$ \\
\hline 1 & 17 & 35.514 & 0.6 & 4.8 \\
\hline 2 & 16 & 38.649 & 0.6 & 4.8 \\
\hline 3 & 16 & 39.397 & 0.8 & 4.8 \\
\hline 4 & 16 & 42.276 & 0.8 & 5.4 \\
\hline 5 & 16 & 42.528 & 0.5 & 5.2 \\
\hline 6 & 19 & 43.637 & 0.6 & 4.5 \\
\hline 7 & 19 & 44.333 & 0.6 & 4.6 \\
\hline 8 & 19 & 45.586 & 0.8 & 4.8 \\
\hline 9 & 18 & 47.804 & 0.4 & 4.8 \\
\hline 10 & 19 & 47.939 & 0.6 & 4.7 \\
\hline 11 & 23 & 47.997 & 0.4 & 4.7 \\
\hline 12 & 21 & 48.083 & 0.7 & 4.5 \\
\hline 13 & 18 & 49.122 & 0.8 & 4.8 \\
\hline 14 & 23 & 49.633 & 0.4 & 4.7 \\
\hline 15 & 21 & 50.598 & 0.4 & 4.8 \\
\hline 16 & 24 & 50.853 & 0.4 & 4.2 \\
\hline 17 & 18 & 52.317 & 0.4 & 5.5 \\
\hline 18 & 20 & 52.560 & 0.8 & 5.5 \\
\hline 19 & 18 & 55.393 & 0.4 & 5.8 \\
\hline \multicolumn{5}{|l|}{ Weight average $=46.538 \mathrm{~kg}$} \\
\hline
\end{tabular}

\begin{tabular}{|c|c|c|c|c|}
\hline \multicolumn{5}{|c|}{ The weight and diameter of medium bamboo } \\
\hline No & NP & $\begin{array}{c}\text { Weight } \\
(\mathrm{kg})\end{array}$ & $\begin{array}{c}\text { DPmin } \\
(\mathrm{cm})\end{array}$ & $\begin{array}{c}\text { DPmax } \\
(\mathrm{cm})\end{array}$ \\
\hline 1 & 24 & 57.468 & 0.8 & 5.5 \\
\hline 2 & 24 & 57.617 & 0.8 & 4.8 \\
\hline 3 & 19 & 57.826 & 1.1 & 5.2 \\
\hline 4 & 16 & 58.382 & 0.8 & 6.4 \\
\hline 5 & 24 & 58.638 & 0.9 & 5.8 \\
\hline 6 & 24 & 59.050 & 1.0 & 4.8 \\
\hline 7 & 16 & 59.066 & 1.2 & 6.2 \\
\hline 8 & 17 & 59.235 & 0.4 & 5.8 \\
\hline 9 & 24 & 59.388 & 0.5 & 4.8 \\
\hline 10 & 24 & 61.306 & 0.6 & 5.3 \\
\hline 11 & 24 & 61.323 & 1.2 & 4.8 \\
\hline 13 & 20 & 61.405 & 1.3 & 6.2 \\
\hline 14 & 24 & 62.689 & 0.6 & 5.3 \\
\hline 15 & 19 & 66.157 & 0.6 & 5.8 \\
\hline 16 & 21 & 71.558 & 0.7 & 5.2 \\
\hline 17 & 25 & 71.695 & 0.6 & 5.3 \\
\hline 18 & 27 & 72.717 & 0.8 & 5.2 \\
\hline 19 & 24 & 73.753 & 0.6 & 5.5 \\
\hline 20 & 24 & 74.805 & 0.8 & 5.7 \\
\hline Weight average $=63.271 \mathrm{~kg}$ & & \\
\hline
\end{tabular}

\begin{tabular}{|c|c|c|c|c|}
\hline \multicolumn{5}{|c|}{ The weight and diameter of large bamboo } \\
\hline No & NP & $\begin{array}{c}\text { Weight } \\
(\mathrm{kg})\end{array}$ & $\begin{array}{c}\text { DPmin } \\
(\mathrm{cm})\end{array}$ & $\begin{array}{c}\text { DPmax } \\
(\mathrm{cm})\end{array}$ \\
\hline 1 & 23 & 79.210 & 0.6 & 5.5 \\
\hline 2 & 23 & 80.222 & 0.8 & 5.5 \\
\hline 3 & 24 & 80.584 & 0.6 & 5.9 \\
\hline 4 & 24 & 87.093 & 0.6 & 5.5 \\
\hline 5 & 20 & 88.620 & 0.8 & 6.3 \\
\hline 6 & 19 & 93.404 & 2.1 & 6.3 \\
\hline 7 & 20 & 98.946 & 1.3 & 6.3 \\
\hline Weight average $=88.869 \mathrm{~kg}$ \\
\hline
\end{tabular}




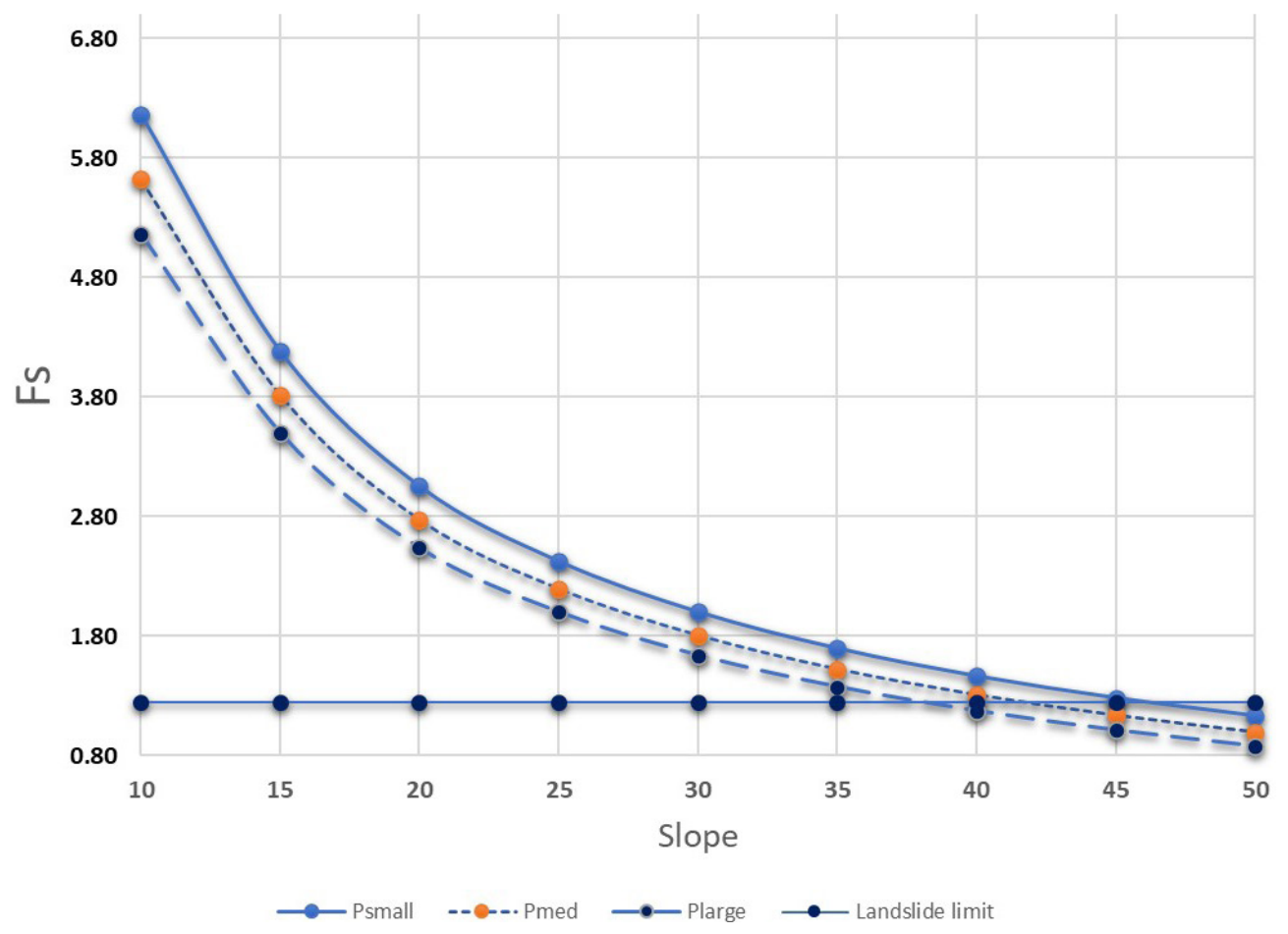

Figure 4. Estimated safety factor due to the weight of bamboo

reaches a greater condition, then the chance of landslides is also higher. The increase in the number of bamboo sticks with a large diameter is a sign of an increased risk of landslides.

At a slope angle of $40^{\circ}$, the presence of plarge bamboo causes landslides. Even worse conditions occur at $45^{\circ}$ and $50^{\circ}$ angles, and bamboo vegetation causes sliding in the riverbank. This indicates that the slope angle of $40^{\circ}$ is not feasible to use bamboo as reinforcement for the cliff.

\section{DISCUSSION}

The riverbanks that are equipped with riparian ecosystems contribute to the physical quality of the river. This premise was supported by the Hubble study [Hubble et al., 2010] which stated that plant roots contribute to the reduced risk of landslides due to root strengthening. Therefore, the riparian root system was effective in increasing slope stability. Furthermore, the growth of riparian vegetation usually acts as a floodplain that can maintain the quality of the river. The presence of vegetation minimizes sedimentation as a series of erosion events. As a result, the river bed topography was better preserved and maintained river capacity [Lin et al., 2011] and [Hubble et al., 2010].
Bamboo plants on the riverbank can function as erosion protection. This study has proven that the presence of bamboo can increase the value of the safety factor. The extensive root cohesion causes an increase in soil particle bonding. As a result, the value of a security is even greater. However, the growth or addition of bamboo pole decreases the safety factor of land. The discoveries of this study practically provided a guide for nonstructural river management methods where bamboo vegetation is one of the right choices.

Bamboo, with its distinctive morphology made of several polishes, is relatively easy to manage. The harvesting or releasing of some of its parts is an effort that can maintain the weight of the bamboo plant. Harvesting of parring bamboo at the research location is closely related to the local wisdom of the community. This bamboo is used as a traditional building material and the primary material in local traditional processions. Therefore, parring bamboo is very important for lives of local people. The habit of using bamboo supports soil bioengineering techniques in the Walanae watershed.

This study also proposed the protection of the ground surface to maintain the slope. The safety of surface erosion on riverbanks is an effort to maintain the ground-level slope. Surface erosion or the release of the soil surface due to water flow can 
be reduced by various methods. Litter covering treatment can improve the soil erosion resistance. The litter layer is very influential in the magnitude of the kinetic energy of rain on the soil surface. Without a surface cover, raindrops can hit the soil surface and cause the surface layer to be released [Wang et al., 2020]. Mechanically, this process takes place continuously and causes an increase in the slope of the slope. Bamboo plants can protect the soil surface from the direct hit of raindrops. Several studies have shown that the thickness of litter layer in the forests regarding weathering of bamboo leaves [Seitz et al., 2015] and [Hairiah, et al., 2006]. Bamboo vegetation with thin and small leaves with a pointed shape and the texture like paper is easy to fall off. The release of leaves from the stems causes accumulation on the soil surface and influences the thickness of the litter layer [Nath et al., 2011]. The idea is to the strengthen reason that the bamboo plant system can also prevent the increase in slopes on riverbanks.

Bamboo weight management and cliff erosion protection also prevent toe erosion from occurring at the base of a slope. [Shu et al., 2019] described that the collapse rate of riverbanks has a positive correlation with flow velocity, water depth, and soil bearing capacity. Figure 5 illustrates the process of toe erosion and cliff collapse. The frictional force of water flow in the foot of cliff trigger the erosion process began with the peeling soil. Figure $5 \mathrm{~b}$ shows that the presence of bamboo caused the additional weight of soil that is the way the roots of the plants could not carry them. This implies that the significant weight as a burden at the foot of the cliff triggered the collapse. As a result, cliffs collapse, and the vegetation on the riverbanks will also be released.

Soil bioengineering is feasible to be implemented as a riverbank protection technique, as the long the community maintains the growth of bamboo and the slope of riverbank. The sustainability of the parring bamboo vegetation at Walanae Watershed contributes to ecological protection. It prevents the degradation of land and water resources.

\section{CONCLUSIONS}

On the basis of the results obtained and numerical analysis of silty riverbank, the authors conclude that the bamboo vegetation on the Walanae riverbanks is divided into three categories based on the weight of clumps. The small category has an average weight of $46.538 \mathrm{~kg}$. The medium type has an average weight of $63.271 \mathrm{~kg}$, and the large bamboo weighing is $88.869 \mathrm{~kg}$. The increase in weight was caused by the addition of the number of stems.

The numerical analysis results indicate that the presence of bamboo vegetation increases the risk of cliff landslides. Therefore, as its weight increases, it contributes to a decrease in the value of the safety factor. The application of bamboo vegetation as slope protection is not possible in the slope angles greater than $40^{\circ}$. The soil bioengineering technique with bamboo vegetation on riverbanks should consider the reduction in the number of polishes in each clump. Harvesting activities are the solution for this technique. a)

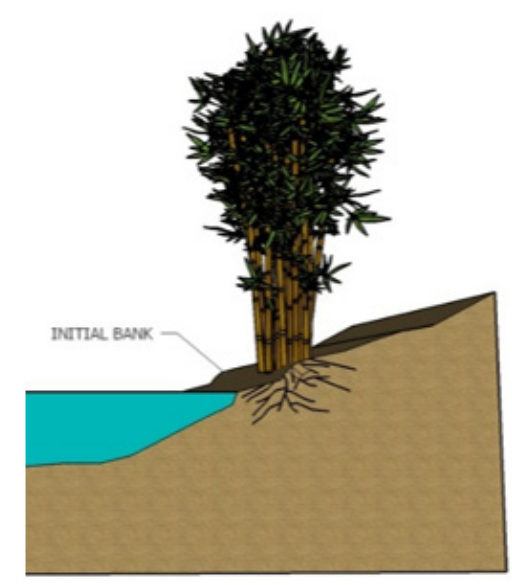

b)

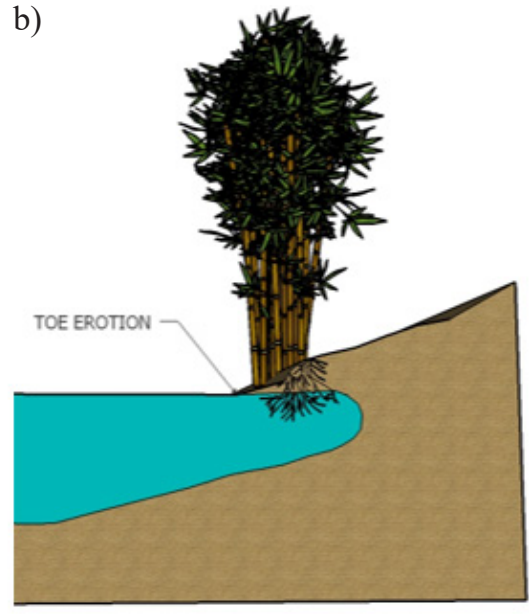

c)

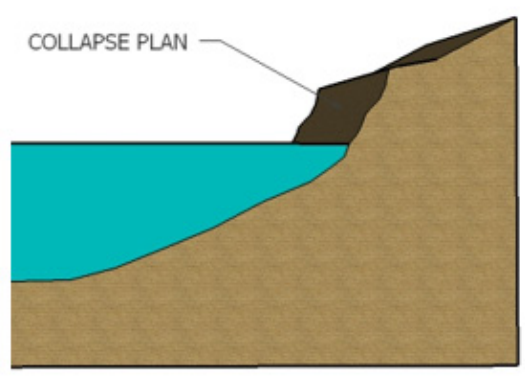

Figure 5. The mechanism of cliff collapse on the riverbank 


\section{Acknowledgements}

The authors express gratitude for the contribution of funds through the financing scheme "Acceleration of Professors through the Institute for Research and Community Service, Universitas Negeri Makassar Year of 2020".

\section{REFERENCES}

1. Abernethy B. \& Rutherfurd I.D. 2000. Does the weight of riparian trees destabilize riverbanks? Regul. Rivers Res. Manag. An Int. J. Devoted to River Res. Manag., 16(6), 565-576.

2. Bischetti G.B., De Cesare G., Mickovski S.B., Rauch H.P., Schwarz M., Stangl R. 2021. Design and temporal issues in Soil Bioengineering structures for the stabilisation of shallow soil movements. Ecol. Eng., 169, 106309.

3. Bordoloi S., Ng C.W.W. 2020. The effects of vegetation traits and their stability functions in bio-engineered slopes: A perspective review. Eng. Geol., 105742.

4. Cislaghi A.E., Chiaradia A., Bischetti G.B. 2017. Including root reinforcement variability in a probabilistic 3D stability model. Earth Surf. Process. Landforms, 42(12), 1789-1806.

5. Cislaghi A.E., Chiaradia A., Bischetti G.B. 2018. A probabilistic multidimensional approach to quantify large wood recruitment from hillslopes in mountainousforested catchments. Geomorphology, 306, 108-127.

6. De Baets S., Torri D., Poesen J., Salvador M.P., Meersmans J. 2008. Modelling increased soil cohesion due to roots with EUROSEM. Earth Surf. Process. Landforms J. Br. Geomorphol. Res. Gr., 33(13), 1948-1963.

7. Dietrich W.E., McKean J., Bellugi D., Perron T. 2007. The prediction of shallow landslide location and size using a multidimensional landslide analysis in a digital terrain model, in In: Chen, CL; Major, JJ, editors. Proceedings of the Fourth International Conference on Debris-Flow Hazards Mitigation: Mechanics, Prediction, and Assessment (DFHM4); Chengdu, China, September 10-13, 2007. The Netherlands, Amsterdam: IOS Press. 12.

8. Gasser E. et al.. 2019. A review of modeling the effects of vegetation on large wood recruitment processes in mountain catchments. Earth-Science Rev., 194, 350-373.

9. Gasser E., Perona P., Dorren L., Phillfips C., Hübl J., Schwarz M. 2020. A new framework to model hydraulic bank erosion considering the effects of roots. Water, 12(3), 893.

10. Guo W.Z. et al.. 2020. Telling a different story: The promote role of vegetation in the initiation of shallow landslides during rainfall on the Chinese Loess Plateau, Geomorphology, 350, 106879.

11. Hairiah D.K., Sulistyani H., Suprayogo D., Purnomosidhi P., Widodo R.H., Van Noordwijk M. 2006. Litter layer residence time in forest and coffee agroforestry systems in Sumberjaya, West Lampung, For. Ecol. Manage., 224(1-2), 45-57.

12. Lin C., Yang Y., Guo J., Chen G., Xie J. 2011. Fine root decomposition of evergreen broadleaved and coniferous tree species in mid-subtropical China: dynamics of dry mass, nutrient and organic fractions. Plant Soil, 338(1-2), 311-327.

13. Lu C., Chen S., Jiang Y., Shi J., Yao C., Su X. 2018. Quantitative analysis of riverbank groundwater flow for the Qinhuai River, China, and its influence factors. Hydrol. Process., (32)17, 2734-2747.

14. McMahon J.M. et al.. 2020. Vegetation and longitudinal coarse sediment connectivity affect the ability of ecosystem restoration to reduce riverbank erosion and turbidity in drinking water. Sci. Total Environ., 707, 135904.

15. Mao Z. et al.. 2012. Engineering ecological protection against landslides in diverse mountain forests: choosing cohesion models, Ecol. Eng., 45, 55-69.

16. Nath A.J. \& Das A.K. 2011. Decomposition dynamics of three priority bamboo species of homegardens in Barak Valley, Northeast India, Trop. Ecol., 52(3), 325-330.

17. Pollen N., Simon A. 2005. Estimating the mechanical effects of riparian vegetation on stream bank stability using a fiber bundle model. Water Resour. Res., 41(7).

18. Recking A., Piton A., Montabonnet L., Posi S., Evette A. 2019. Design of fascines for riverbank protection in alpine rivers: Insight from flume experiments. Ecol. Eng., 138, 323-333.

19. Rey F. et al.. 2019. Soil and water bioengineering: Practice and research needs for reconciling natural hazard control and ecological restoration. Sci. Total Environ., 648, 1210-1218.

20. Schmitt K., Schäffer M., Koop J., Symmank. 2018. River bank stabilisation by bioengineering: potentials for ecological diversity, J. Appl. Water Eng. Res., 6(4), 262-273.

21. Shen P., Zhang L.M., Chen H.X., Gao L. 2017. Role of vegetation restoration in mitigating hillslope erosion and debris flows. Eng. Geol., 216, 122-133.

22. Seitz S. et al.. 2015. The influence of leaf litter diversity and soil fauna on initial soil erosion in subtropical forests, Earth Surf. Process. Landforms, 40(11), 1439-1447.

23. Shu A., Duan G., Rubinato M., Tian L., Wang M., Wang S. 2019. An experimental study on mechanisms for sediment transformation due to riverbank collapse, Water, 11(3), 529.

24. Wang L., Zhang G., Zhu P., Wang X. 2020. Comparison of the effects of litter covering and incorporation 
on infiltration and soil erosion under simulated rainfall. Hydrol. Process., 34(13), 2911-2922.

25. WSDOT. 2005. Geotechnical design manual M4603." Washington State Department of Transportation Olympia, WA.

26. Wu T.H. \& Watson A. 1998. In situ shear tests of soil blocks with roots. Can. Geotech. J., 35(4), 579-590.
27. Yuen J.Q., Fung T., Ziegler A.D. 2017. Carbon stocks in bamboo ecosystems worldwide: Estimates and uncertainties, For. Ecol. Manage., 393, 113-138.

28. Zhang H., Zhao Z., Ma G., Sun L. 2020. Quantitative evaluation of soil anti-erodibility in riverbank slope remediated with nature-based soil bioengineering in $\mathrm{Li}$ aohe River, Northeast China, Ecol. Eng., 151, 105840. 